\title{
A Novel Method for Contingency Ranking Based On Voltage Stability Criteria in Radial Distribution Systems
}

\author{
Manjunatha Babu Pattabhi ${ }^{1,2} \cdot$ Bangalore Rangappa Lakshmikantha $^{3} \cdot$ Krishna Shanmukha Sundar $^{3}$
}

Received: 19 May 2021 / Accepted: 26 January 2022 / Published online: 19 February 2022

(c) The Author(s), under exclusive licence to Springer Nature Singapore Pte Ltd. 2022

\begin{abstract}
Voltage stability margin regarding with contingency ranking in radial distribution system using novel method is proposed in this paper. Two new indices are derived to forecast the voltage stability in the radial distribution feeders. Here, RSI_N(r) is the radial stability index calculated for each bus and utilized for forecasting the voltage stability. The second index is derived by finding the effect of receiving end voltage change on voltage stability index at a specific bus. Contingency planning by delta analysis method improves the reliability of the system. The proposed system is employed for optimally ranking the contingencies. Impact on voltage stability due to contingencies like loss of FACTS devices, loss of distributed generation (DG) sets and loss of lines is carried out on radial distribution feeders and compared the experimental results with the proposed method using MATLAB platform. The proposed indices are implemented on the test systems and outcomes are compared to existing indices on literature and it is viewed that the proposed indices are effective on predicting the system stability. Contingency due to a loss of DG set, due to a loss of reactive source, due to a loss of line, due to loss of DG set are the considered test cases. Voltage profile improvement using Static VAR Compensator (SVC)-DSTATCOM is also employed in this paper. The proposed system is also tested under 15, 28 bus system, IEEE-69 and 123 bus system.
\end{abstract}

Keywords Radial Stability Index (RSI) · Voltage Stability Improvement (VSI) · Radial distribution system · Radial System Sensitivity Index (RSSI) · Distributed generation (DG) · Delta Analysis

$\begin{array}{ll}\text { Abbreviations } \\ V_{s} \quad \text { sending end voltage } \\ \delta_{s} \quad \text { Phase angle of sending end voltage } \\ \delta_{r} \quad \text { phase angle of receiving end voltage } \\ V_{r} \quad \text { Voltage in receiver end } \\ Z & \text { impedance of branch } \\ R & \text { Resistance } \\ X & \text { reactance } \\ P & \text { Active power load } \\ Q & \text { reactive power load }\end{array}$

Manjunatha Babu Pattabhi

manjubabup@gmail.com

1 BMS Institute of Technology and Management, Bengaluru, Karnataka, India

2 Department of Electrical and Electronics Engineering, Visvesvaraya Technological University, Belagavi, Karnataka, India

3 Department of Electrical and Electronics Engineering, Dayananda Sagar Academy of Technology and Management, Bengaluru, Karnataka, India

\begin{tabular}{|c|c|}
\hline$Z_{e q u}$ & $\begin{array}{l}\text { Equivalent impedance of the branch connecting } \\
\text { source to receiving end }\end{array}$ \\
\hline$R_{e q u}$ & $\begin{array}{l}\text { equivalent resistance of the branch connecting } \\
\text { source to receiving end }\end{array}$ \\
\hline$X_{e q u}$ & $\begin{array}{l}\text { Equivalent reactance of the branch connecting } \\
\text { source to receiving end }\end{array}$ \\
\hline$R S I \_N_{(r)}$ & radial stability index \\
\hline$g$ & Generator bus \\
\hline$l$ & load bus \\
\hline RSI & Radial Stability Index \\
\hline VSI & Voltage Stability Improvement \\
\hline RSSI & Radial System Sensitivity Index \\
\hline $\mathrm{DG}$ & Distributed generation \\
\hline ROW & Right of way \\
\hline
\end{tabular}

\section{Introduction}

Due to the rapid industrial growth and spread of larger residential areas the stress on electrical distribution network is increasing many folds. Right of way (ROW) issue in the urban areas is one of the bottlenecks to expand the 
distribution network with the demand. Voltage collapse is the limiting factor, as electrical utilities try for increasing the use of its distribution network capabilities for transporting real power. With the introduction of newer technologies like net metering, many end users are installing renewable energy systems and injecting power into the grid $[6,7,26]$. An unplanned disturbance if not handled properly would spread to the transmission system and would result in grid collapse [20]. The distribution networks of today not only passively deliver power from the transmission network, via the distribution network to the end customer but also inject power into the grid with the introduction of distributed generation. System operators should possess adequate knowledge on what are the action needs to be taken when system experiences a contingency. The classification of unsafe contingencies by its severity is called contingency classification and important for power system operators and planners $[2,9$, 10, 19]. Many FACTS devices are also connected in distribution systems to maintain power factor, reduce power loss, and recover system voltage stability [16, 21, 24]. In [5, 23] the load flow equations of the radial network are modified and an innovative voltage stability index is proposed. A new voltage stability index is derived from squaring the received active and reactive power in load end from the load flow equations for radial networks. [4, 18, 25]. Introduction of the DG and FACTS devices in the distribution would reduce the system losses and also can enhance the system stability. Contingencies like loss of line or loss of embedded generator or loss of a reactive power device or unplanned maintenance to attend an emergency would increase the risk of voltage instability $[4,14]$. At present only few electrical utilities are carrying out voltage stability and contingency analysis of distribution systems.

A new index of voltage stability from load flow equations is presented in the literature for determining the bus that is prone to voltage instability for radial distribution networks [22]. For the analysis of voltage stability, an equivalent system of two buses of a distribution network is utilized. [11, 12], But, the variation of indices with the placement of DG is not studied in the literature. An attempt is made to study the impact of placement of DG in the voltage stability indices proposed in $[8,22,22]$.

A PQ or PV node is used for DG modeling, where the PQ node models are treated as negative injections into the system [15]. In future it will be mandatory for all utilities and system planners to conduct contingency analysis on distribution systems. In literature contingency ranking analysis is done for the transmission systems [1,3] in detail but for the distribution system only limited literature is available.

Voltage stability margin regarding with contingency ranking in radial distribution system using novel method is proposed in this paper. Two new indices of voltage stability are derived to forecast the voltage stability for the radial distribution feeders. Rest of the paper is organized in the following: Sect. 2 provides the radial stability index. Section 3 explains the derivation of proposed delta analysis method. Section 4 delineates the experimental results. Section 5 provides the conclusion.

\section{Radial Stability Index (SI)}

In [16] a voltage stability index has been proposed depending on the existence of real and reactive power solutions at receiving end. In [20], a voltage stability index is proposed for radial distribution system and given by Eq. (1). Figure 1 shows the electrical equivalent.

$R S I(r)=2 V_{s}^{2} V_{r}^{2}-V_{r}^{4}-2 V_{r}^{2}(P R+Q X)-|Z|^{2}\left(P^{2}+Q^{2}\right)$

For stable operation of radial distribution networks, $R S I(r) \geq 0$ for $\mathrm{r}=2,3,4$. where $V_{s}$ is the sending end voltage, $\delta_{s}$ is the phase angle of sending end voltage, $\delta_{r}$ is the phase angle of receiving end voltage, $V_{r}$ is voltage in receiver end, $Z$ is impedance of branch, $R$ is resistance, $X$ is reactance, $P$ is active power load, $Q$ is reactive power load, voltage stability node index $r(r=2,3,4 \ldots \ldots)$.

\section{Derivation of Proposed Radial Voltage Stability Indices}

The stability index given in Eq. (1) is used to derive the Radial Voltage Stability Index. Sending voltage $\left(V_{s}\right)$ in the equation $R S I(r)$ is made to unity and the branch resistance and reactance are modified with equal resistance and reactance as source bus to receiving bus. A resultant equation with the above mentioned changes is given as

RSI_N(r) $=2 \mathrm{~V}_{\mathrm{r}}^{2}-\mathrm{V}_{\mathrm{r}}^{4}-2 \mathrm{~V}_{\mathrm{r}}^{2}\left(\mathrm{PR}_{\text {equ }}+\mathrm{QX}\right.$ equ $)-\left|\mathrm{Z}_{\text {equ }}\right|^{2}\left(\mathrm{P}^{2}+\mathrm{Q}^{2}\right)$

$Z_{\text {equ }} \quad Z_{\text {bus }}(r, r)$,

$R_{\text {equ }} \quad$ Real part of $\left(Z_{\text {bus }}(r, r)\right)$,

$X_{\text {equ }}$ Imaginary part of $\left(Z_{\text {bus }}(r, r)\right)$.

where $Z_{\text {equ }}$ is the equivalent impedance of the branch connecting source to receiving end, $R_{\text {equ }}$ is the equivalent

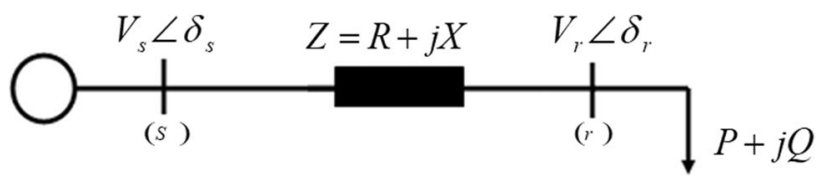

Fig. 1 Electrical equivalent 
resistance of the branch connecting source to receiving end, $X_{e q u}$ is the equivalent reactance of the branch connecting source to receiving end. $R S I \_N(r)$ is radial stability index calculated for each bus and utilized for forecasting the voltage system stability. Once the receiving end voltages are known from the load flow then it can be calculated very easily.

The second index is derived by finding the effect of receiving end voltage change on voltage stability index (1) at a specific bus; $R S I(r)$ is differentiated with respect to change in the receiving end voltage $V_{r}$. Upon differentiation, obtain a change within $\operatorname{RSI}(r)$ regarding with change on receiving end voltage $V_{r}$.

$\frac{\Delta R S I(r)}{\Delta V(r)}=4 V_{r}-4 V_{r}^{3}-4 V_{r}(P R+Q X)=R S I \_P(r)$

Voltages, resistance, and reactance are modified with equal source voltage, resistance, and reactance as source to bus in deliberation. $R S I \_P(r)$ is calculated for each bus and it can be used as an alternate index to forecast the voltage system stability.

\section{Bus Electrical Radial System}

The analysis of indices $R S I \_N(r)$ and $R S I \_P(r)$ is done on the 15 bus rural electrification distribution system. Table 9 in the Appendix 1 gives the line and load data. The index derived in Eq. (2) is compared with the index in Eq. (1) and the SI index proposed in [2]. SI index is the stability index consequent as divergence of load flow equations and it's valid only for the radial systems. Pattern of variation of indices with respected to bus number is plotted in the Fig. 2.

From Fig. 3 it can be observed that the variation of $R S I \_N(r)$ which is derived from $R S I(r)$ Eq. (1) and the conventional radial distribution stability indices $R S I(r)$ Eq. (1), SI [2] is almost the same. Pattern of variation of indices are important than the absolute values. Once the pattern of variation is matching then the proposed indices can be used for any bus system. It can be observed that the $12^{\text {th }}$ bus is

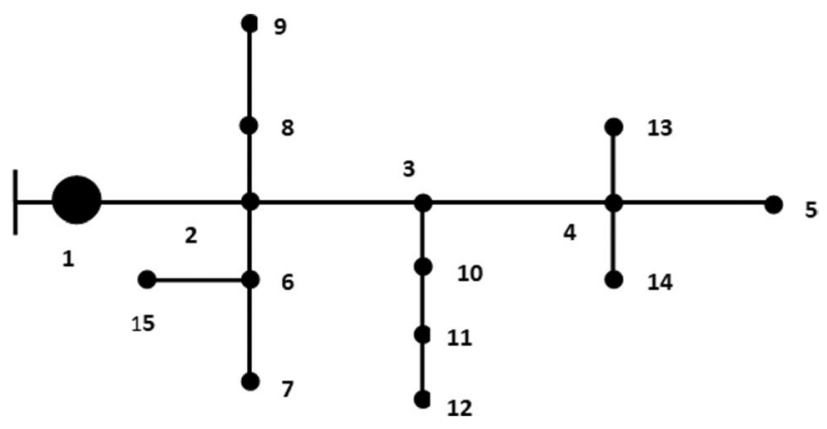

Fig. 215 bus radial distribution system

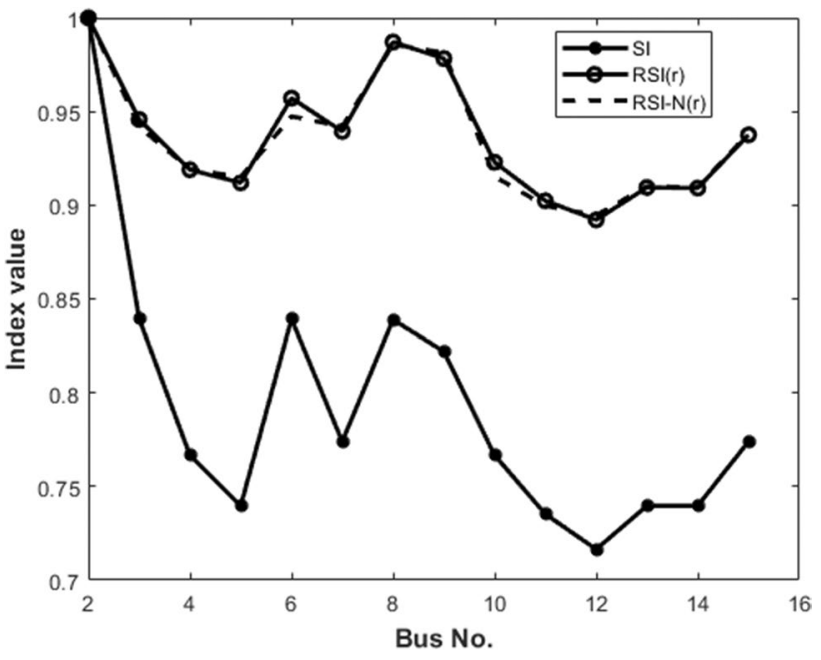

Fig. 3 Pattern of variation of indices

forecasted from bus that is susceptible to voltage instability from 3 indices.

L-index is one of the most primitive voltage stability index proposed on literature [10]. L-Index is used to predict the voltage stability of radial and meshed power systems.

$L_{j}=\left|1-\sum_{i=1}^{i=g} F_{j i} \frac{V_{i}}{V_{j}}\right|$

here " $g$ ":- implies generator bus, " $l$ ":- implies load bus. An L-index value among 1 and near with 0 implies great voltage stability margin. The buses with maximum value of $L$-index (near with 1) are deemed from critical lines. The pattern of variation of index $R S I \_P(r)$ given by Eq. (3) and L-Index proposed in [10] is plotted in Fig. 4.

It is evident from the Fig. 4 that the pattern of variation of the indices is same. Most sensitive bus towards voltage instability as predicted from L-Index and $R S I \_P(r)$ is $12^{\text {th }}$ bus.

\section{8 bus electrical radial system}

The analysis of indices $R S I \_N(r)$ and $R S I \_P(r)$ is done on the 28 bus rural electrification distribution system. Table 10 in the Appendix 1 gives the line and load data. The index derived in Eq. (2) is compared with the index in Eq. (1) and the SI index proposed in [2]. Figure 5 shows the 28 bus radial distribution system. Figure 6 shows the plot of pattern of variation of indices with respect to bus number.

From Fig. 6 it can be observed that the variation of $R S I \_N(r)$ which is derived from RSI(r) equation and the conventional radial distribution stability index SI [2] is almost the same. It can be observed that the $18^{\text {th }}$ bus is forecasted from bus that is susceptible to voltage 


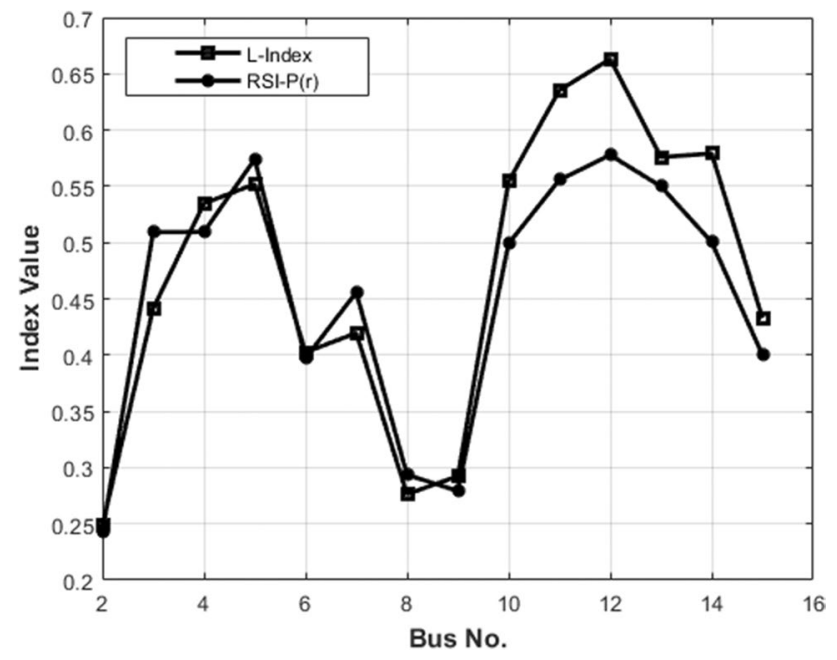

Fig. 4 Plot of pattern of variation of RSI_P(r) and L-Index

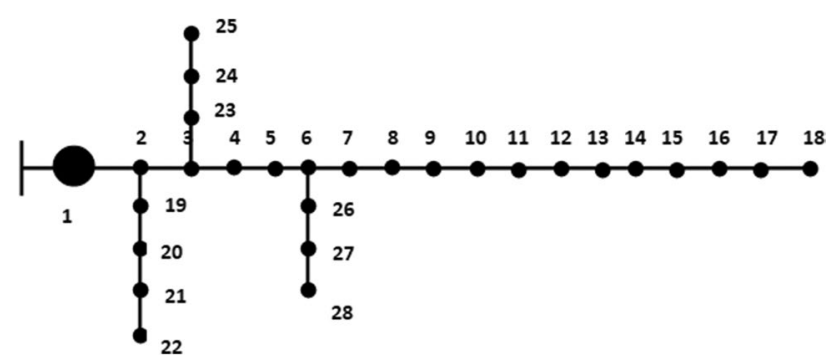

Fig. 528 bus radial distribution system

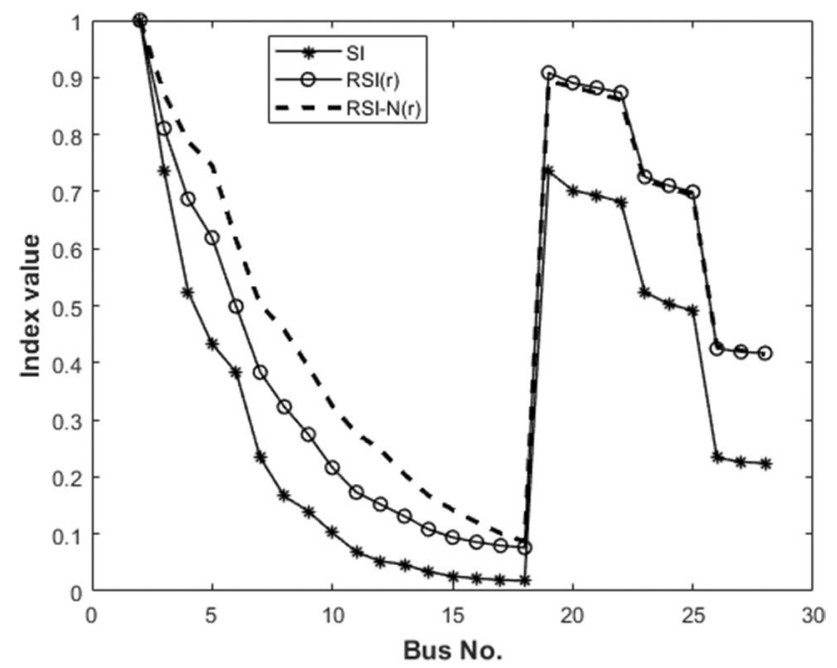

Fig. 6 Pattern of variation of indices

instability from 3 indices. Similarly, pattern of variation of indices as plotted in Fig. 7 is plotted for Eq. (3) and L-Index proposed [10]. L-Index is one of the most

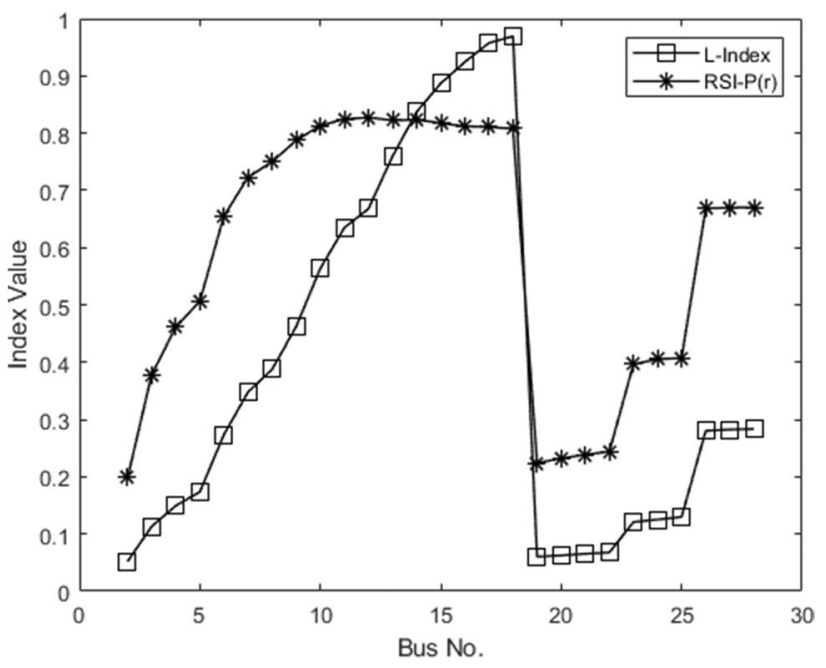

Fig. 7 Plot of pattern of variation of RSI_P(r) and L-Index

primitive indexes utilized for predicting the voltage stability of both radial and meshed systems. It is evident from the Fig. 7 shows variation pattern of the indices is similar and $18^{\text {th }}$ bus is predicted as most instable bus by both L-Index and RSI-P(r). From Figs. 4 and 7 it can be concluded that $R S I \_P(r)$ can be used as an alternate index to forecast the voltage stability of the radial bus systems.

\section{Derivation of Proposed Delta Analysis Method}

The linearized power flow equations is given below

$\left[\begin{array}{c}\Delta P \\ \Delta Q\end{array}\right]=\left(\begin{array}{cc}H & N \\ M & L\end{array}\right)\left[\begin{array}{c}\Delta \theta \\ \Delta \mathrm{V}\end{array}\right]$

$\Delta P=J_{11} \Delta \theta+J_{12} \Delta V$

$\Delta Q=J_{21} \Delta \theta+J_{22} \Delta V$

Rewriting Eq. 5 in terms of $\Delta \theta$ we get

$\Delta \theta=J_{11}^{-1} \Delta P-J_{11}^{-1} J_{12} \Delta V$

Substituting $\Delta \theta$ in Eq. (6) we get

$$
\begin{gathered}
\Delta Q=J_{21} J_{11}^{-1} \Delta P-J_{21} J_{11}^{-1} J_{12} \Delta V+J_{22} \Delta V \\
\left(J_{21} J_{11}^{-1} J_{12}-J_{22}\right) \Delta V=J_{21} J_{11}^{-1} \Delta P \Delta Q \\
\Delta V=\left[J_{21} J_{11}^{-1} J_{12}-J_{22}\right]^{-1}\left[J_{21} J_{11}^{-1} \Delta P-\Delta Q\right]
\end{gathered}
$$

Substituting $\Delta V$ in Eq. 3 we get 


$$
\begin{gathered}
\Delta R S I(r)=\left[4 V_{r}-4 V_{r}^{3}-4 V_{r}(P R+Q X)\right] \\
{\left[\left[J_{21} J_{11}^{-1} J_{12}-J_{22}\right]^{-1}\left[J_{21} J_{11}^{-1} \Delta P-\Delta Q\right]\right]}
\end{gathered}
$$

Equation 9 gives the relationship between the change under RSI index through the change of $P$ and $Q$. This equation is utilized for determining the sensitivity of voltage stability index regarding with injection of reactive power on specified bus. Whenever the system experiences contingency, it would result in the change on real power and reactive power connected to system which in turn changes the voltage system stability. Equation 9 is used for predicting the change in voltage stability at a node due to the change in real and reactive power on system. Due to contingency, there may be a loss of generation (tripping of a DG set) or loss of reactive power source (disconnection of shunt FACTS devices) or both. The change in voltage stability index due to a loss of DG set or due to loss of shunt FACTS device or due to tripping of line can be obtained from Eq. 9. $\sum[\Delta R S I(r)]$ is calculated to compare and rank different contingencies in the system. A higher value of $\sum[\Delta R S I(r)]$ indicates the particular contingency would create greater impact on the system and ranked one.

\section{Experimental Results}

\section{Test case 1: Contingency due to a loss of DG set}

It compares the impact of contingency of DG set on voltage system stability both the proposed and the conventional system. For comparison, the 15 bus system is taken. Figure 2 portrays that one-line diagram with the location of the DG set. The DG set location and rating is selected randomly. Table 9 in Appendix 1 provides the load and line data. Loading of the system is increased five times over the base case indicated in the Table 9 to increase the load on the system. DG set is modeled as a PQ load with negative injection and rating is chosen as $100 \mathrm{~kW}$.

To compare the effectiveness of proposed through conventional method, $\Delta R S I(r)$ for a loss of DG set is calculated from Eq. $9(\Delta \mathrm{Q}=0)$. From the conventional method, $\Delta R S I(r)$ iscalculated as difference in RSI at all the buses before and after removal of DG set. Results are tabulated in Table 1. Figure 8 shows the 15 bus system with a DG set connected at $12^{\text {th }}$ bus.

It may be view as Table 1 , which $\Delta R S I(r)$ from proposed delta analysis and conventional methods are matching closely. It can be observed from the calculated value of $\Delta R S I(r)$ from delta analysis and conventional method is maximum at $12^{\text {th }}$ bus. Delta analysis can be used to in contingency planning to find the effect of any loss of DG set connected to the system. The absolute value of RSI(r) can
Table 1 Comparison of $\Delta R S I(r)$ calculated from delta analysis and conventional method for Test case- 1

\begin{tabular}{llll}
\hline Sl. No & Bus No & $\begin{array}{l}\Delta R S I(r) \\
\text { Delta Analysis } \\
\text { Method }\end{array}$ & $\begin{array}{l}\Delta R S I(r) \\
\text { Conventional Method }\end{array}$ \\
\hline 1 & 2 & 0.0048502 & 0.0045587 \\
2 & 3 & 0.010573 & 0.0093636 \\
3 & 4 & 0.011335 & 0.0095223 \\
4 & 5 & 0.011993 & 0.0085358 \\
5 & 6 & 0.0063141 & 0.0081011 \\
6 & 7 & 0.0066826 & 0.0067091 \\
7 & 8 & 0.005188 & 0.0083352 \\
8 & 9 & 0.0051896 & 0.0079434 \\
9 & 10 & 0.015373 & 0.0097142 \\
10 & 11 & 0.022064 & 0.011376 \\
11 & 12 & 0.02691 & 0.01488 \\
12 & 13 & 0.011985 & 0.0084123 \\
13 & 14 & 0.011597 & 0.0083965 \\
14 & 15 & 0.006468 & 0.0066497 \\
\hline
\end{tabular}

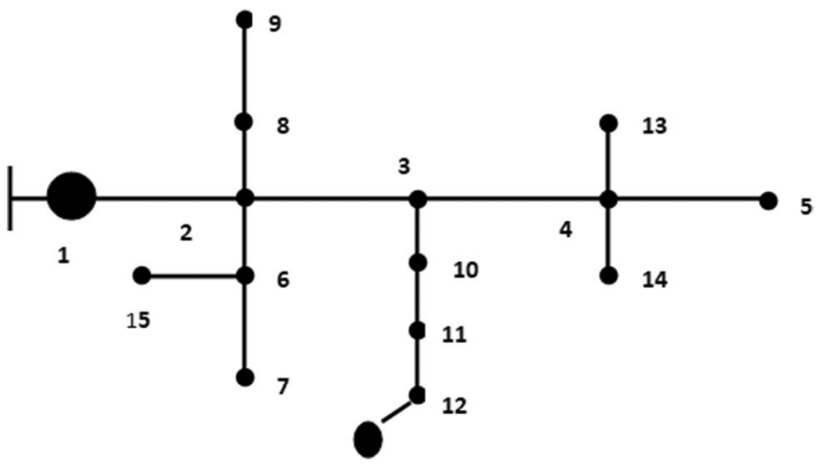

Fig. 815 bus system with a DG set connected at $12^{\text {th }}$ bus

be obtained from adding RSI(r) at a bus with $\Delta R S I(r)$, if the absolute value becomes negative then the system becomes unstable. So, $\Delta R S I(r)$ can be used to predict the bus are having higher probability to become unstable and also predicts the system reliability.

\section{Test case 2: Contingency due to a loss of reactive source}

This section compares the impact of contingency of reactive source set on voltage system stability from proposed method and conventional method. 15 bus radial distribution systems are considered for test. Table 9 on Appendix 1 gives line and load data. Loading of the system is increased five times the base case. A reactive power compensating device can be anything like FACTS devices or Static capacitors is placed the bus no. 13 as shown in Fig. 9. Reactive 


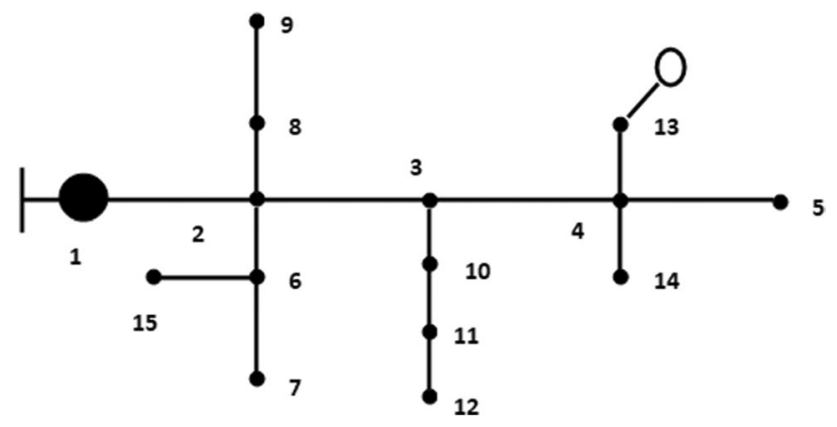

Fig. 915 bus system with a reactive power source connected at 13th bus system

power compensation device location and rating (100kVAr) is selected randomly.

To compare the effectiveness of proposed using the conventional method $\Delta R S I(r)$ for a loss of reactive power compensation device, which is connected to bus no. 13 is calculated from Eq. 9 with $\Delta \mathrm{P}=0$. From the conventional method, $\Delta R S I(r)$ is calculated as difference in RSI at all the buses before and after reactive power compensation device contingency. Results are tabulated on Table 2.

It can be viewed as Table 2, which $\Delta R S I(r)$ from proposed delta analysis and conventional methods are matching closely. It can be observed from the calculated value of $\Delta R S I(r)$ from delta analysis and conventional method is maximum at $13^{\text {th }}$ bus. In practice reactive power elements are connected in the distribution systems for improvement of voltages, reduction of line losses and for improvement of voltage stability. When there is a contingency associated with a reactive power source as done in the above test case the system may become

Table 2 Comparison of $\Delta R S I(r)$ calculated from delta analysis and conventional method for Test case-2

\begin{tabular}{llll}
\hline Sl. No & Bus No & $\begin{array}{l}\Delta R S I(r) \\
\text { Delta Analysis } \\
\text { Method }\end{array}$ & $\begin{array}{l}\Delta R S I(r) \\
\text { Conventional Method }\end{array}$ \\
\hline 1 & 2 & 0.0042278 & 0.0040557 \\
2 & 3 & 0.0092161 & 0.0083178 \\
3 & 4 & 0.011534 & 0.0085912 \\
4 & 5 & 0.012203 & 0.0088801 \\
5 & 6 & 0.0055038 & 0.0071955 \\
6 & 7 & 0.005825 & 0.0059583 \\
7 & 8 & 0.0045222 & 0.0074036 \\
8 & 9 & 0.0045236 & 0.0070554 \\
9 & 10 & 0.0099827 & 0.0083169 \\
10 & 11 & 0.01097 & 0.0072921 \\
11 & 12 & 0.011329 & 0.0066996 \\
12 & 13 & 0.015116 & 0.0098654 \\
13 & 14 & 0.0118 & 0.0087352 \\
14 & 15 & 0.005638 & 0.0059055 \\
\hline
\end{tabular}

unstable. Delta analysis method can be used to calculate $\Delta R S I(r)$ at each bus taking into the consideration of loss of reactive element at any bus. The buses which are having higher change in $\Delta R S I(r)$ are considered as more prone to voltage instability. Even the absolute value of RSI can be obtained from adding $\Delta R S I(r)$ to RSI(r). Contingency planning with delta analysis method would also improve the system reliability.

\section{Test case 3: Contingency due to a loss of line}

This section compares the impact of contingency of a line on voltage system stability both from proposed method and conventional method. For test, 15 bus radial distribution network portrays on Fig. 1 is considered. A DG set of $2250 \mathrm{~kW}$ is connected at $12^{\text {th }}$ bus, the rating of the DG set is taken randomly. It is assumed that there is a fault on the line between $3^{\text {rd }}$ node to $12^{\text {th }}$ node. The relay protecting the line will sense the fault and isolate the faulty section by opening the circuit breaker (CB) shown in the Fig. 10. After the fault has cleared successfully, the system restores to a new state. After the removal of the line connecting the bus 3 to bus 12, the numbers of the nodes are changed as $13^{\text {th }}$ node becomes $10^{\text {th }}, 14^{\text {th }}$ node becomes $11^{\text {th }}$ and $15^{\text {th }}$ node becomes $12^{\text {th }}$ node respectively for carrying out voltage stability analysis.

It can be observed from Table 3. $\Delta$ RSI(r) from proposed delta analysis method and conventional methods are matching closely. Pattern of variation of indices before and after contingency is shown in Fig. 11. From the pattern of variation of indices, it can be seen that the pattern of RSI(r) before contingency is below than the pattern of RSI(r) after contingency which means that the system voltage stability is increased with the loss of line. The same may be confirmed from Fig. 12, as the individual bus voltages increases the voltage system stability improves. The reason for this, due to line loss the total load fed by the source will be reduced and the system voltage magnitudes will be improved which improve the overall voltage

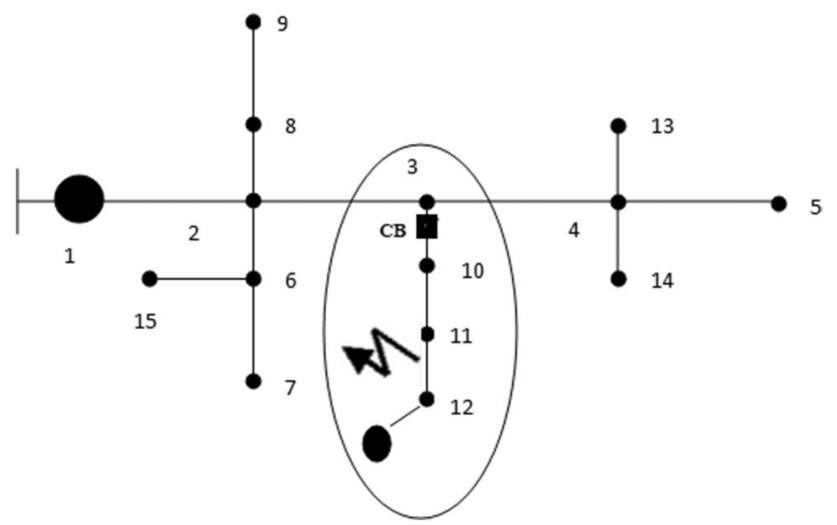

Fig. 1015 bus system with a fault on a spur 
Table 3 Comparison of $\Delta R \operatorname{SI}(r)$ calculated from delta analysis and conventional method for Test case-3

\begin{tabular}{llll}
\hline S1. No & Bus No & $\begin{array}{l}\Delta R S I(r) \\
\text { Delta Analysis } \\
\text { Method }\end{array}$ & $\begin{array}{l}\Delta R S I(r) \\
\text { Conven- } \\
\text { tional } \\
\text { Method }\end{array}$ \\
\hline 1 & 2 & 0.01028 & 0.00371 \\
2 & 3 & 0.021539 & 0.01215 \\
3 & 4 & 0.023786 & 0.01561 \\
4 & 5 & 0.025781 & 0.01442 \\
5 & 6 & 0.017713 & 0.01211 \\
6 & 7 & 0.020612 & 0.01666 \\
7 & 8 & 0.011283 & 0.01155 \\
8 & 9 & 0.011286 & 0.01796 \\
9 & 13 & 0.025738 & 0.01427 \\
10 & 14 & 0.024557 & 0.01425 \\
11 & 15 & 0.018268 & 0.01524 \\
\hline
\end{tabular}

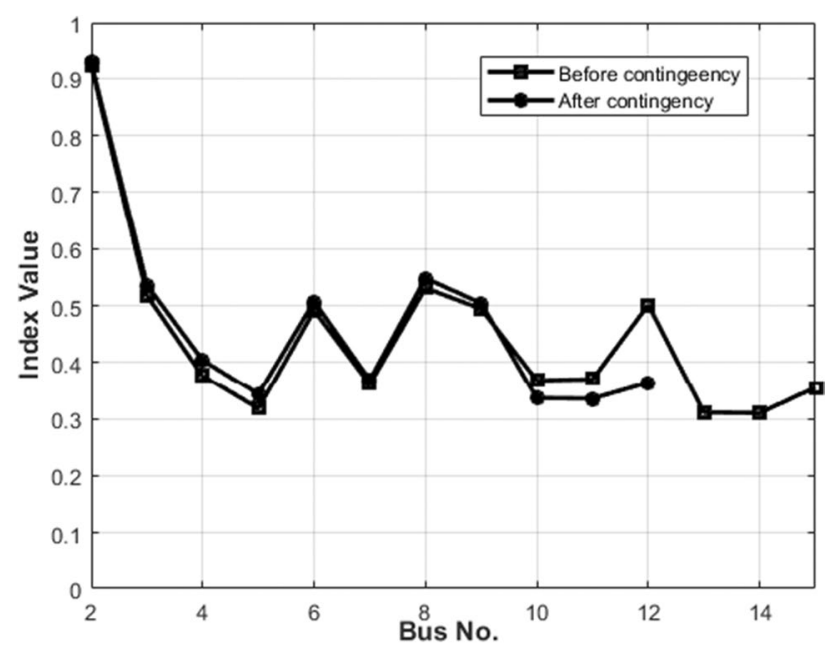

Fig. 11 Pattern of variation of RSI(r) before and after the contingency

system stability. In contrary, if DG set connected at the $12^{\text {th }}$ bus is of higher capacity, then due to loss of this line the voltage stability of the system will be reduced. The reason may be attributed to the fact that loss of line is resulting in a loss of active power source from the system which will effect the overall voltage stability of the system To illustrate this fact, simulation is done with DG set of rating $3750 \mathrm{KW}$ at $12^{\text {th }}$ bus. Pattern of variation of RSI(r) is plotted in Fig. 12 and bus voltages are plotted on Fig. 14. Figure 13, it may be viewed that pattern of RSI(r) before contingency is above than the pattern of RSI(r) after contingency. The same can be observed in Fig. 14, the bus voltages after contingency decreased compared to bus voltages after contingency.

In real time the faults on the distribution systems are unavoidable. The analysis done in the above test case is

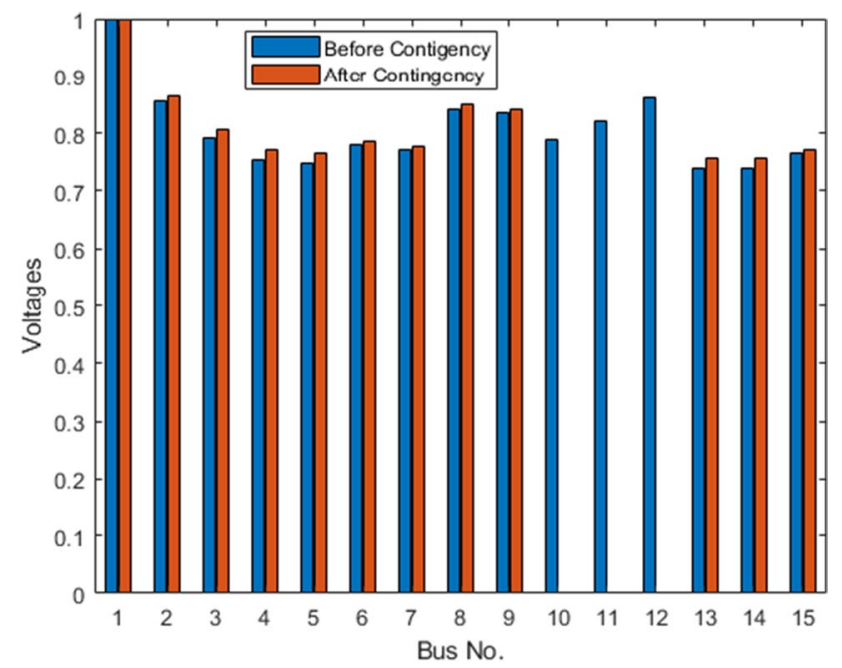

Fig. 12 Bus voltages before and after contingency

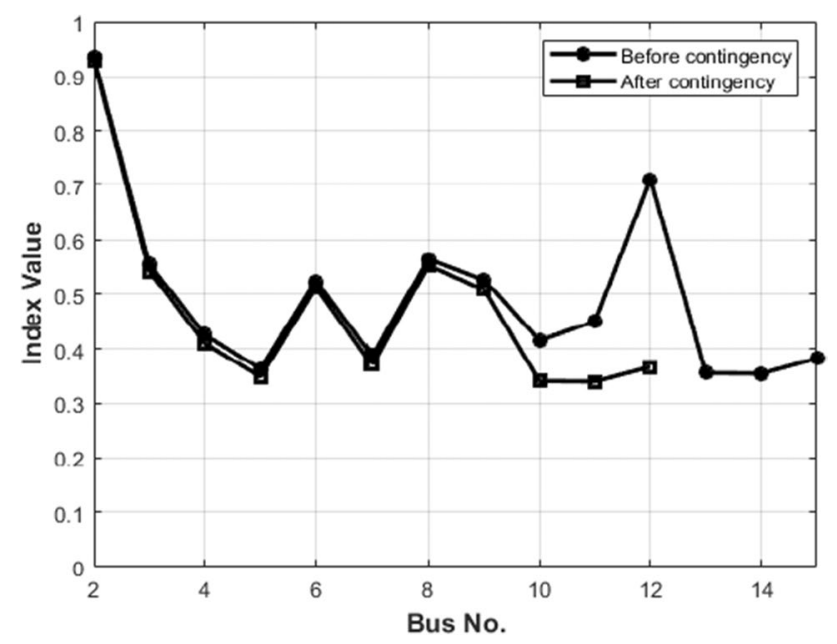

Fig. 13 Pattern of variation of RSI(r) before and after the contingency

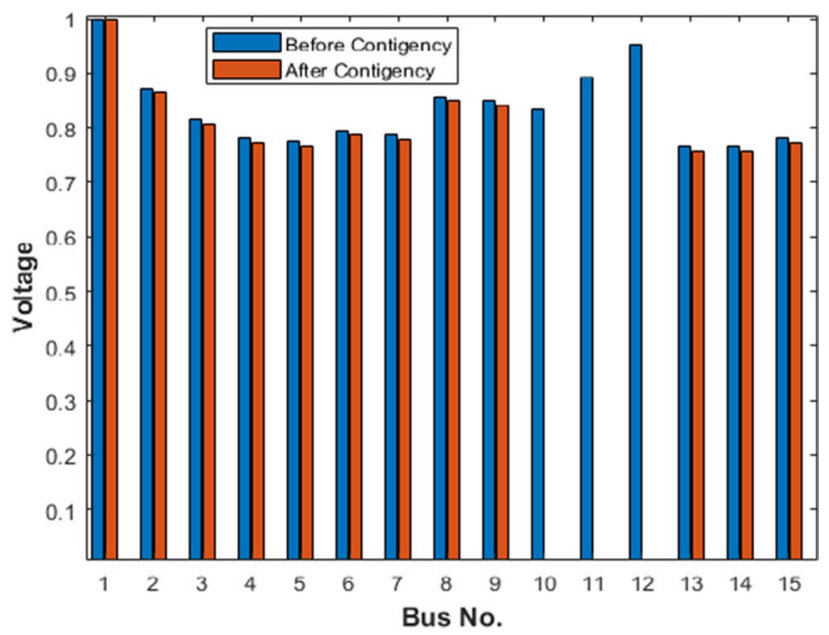

Fig. 14 Bus voltages before and after contingency 


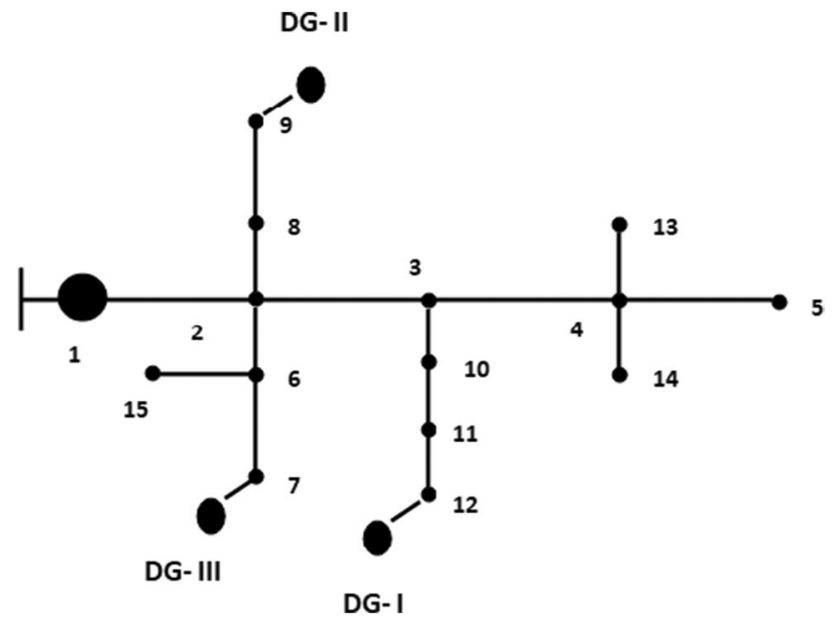

Fig. 1515 bus system with DG set connected at bus no. 7, 9 and 12

Table 4 Indicating the location of DG sets connecting in the 15 bus system

\begin{tabular}{lll}
\hline S1. No & $\begin{array}{l}\text { Name of } \\
\text { the DG set }\end{array}$ & $\begin{array}{l}\text { Con- } \\
\text { nected } \\
\text { bus no }\end{array}$ \\
\hline 1 & DG-I & 12 \\
2 & DG-II & 9 \\
3 & DG-III & 7 \\
\hline
\end{tabular}

very practical. It can be observed that the delta analysis method is effectual at predicting the voltage system stability. The loss of a line or loss of multiple lines can be simulated and voltage stability with the contingencies can be studied.
Test case 4: Contingency ranking due to loss of DG set

This section discusses the procedure of ranking the contingencies for maintaining the system stability based on delta analysis method derived in Sect. 2 . The contingency which reduces the voltage stability of the system as compared to other contingency is ranked one. For test, 15 bus radial distribution network as shown in Fig. 15 is considered 3 no's of DG sets each of rating $100 \mathrm{KW}$ are connected as given in Table 4.

$\Delta$ RSI (R) given in Eq. 8 is calculated for loss of each individual DG set and the results are summarized in Table 5. $\sum[\Delta R S I(r)]$ is calculated for each loss of DG set. It can be seen that the $\sum[\Delta R S I(r)(D G-I)]$ $>\sum[\Delta R S I(r)(D G-I I I)]>\sum[\Delta R S I(r)(D G-I I)]$. Critical ranking of the contingency will be in the order of DG - I (First), DG - III (Second) and DG - II (Third).

The change in the bus voltages before and after contingency of individual DG set is plotted in the Figs 16, 17 and 18 below.

The effect of any contingency on the voltage stability of the entire system may be arrived very easily from delta analysis method.

\section{Voltage profile improvement using SVC - DSTATCOM}

Presently, DSTATCOMs are widely placed in the distribution systems for improvement of the voltages, reduction of line losses and improvement of voltage stability. 15 bus distribution system is analyzed with placement of $1500 \mathrm{kVAr}$ SVC at bus no's $12^{\text {th }}, 13^{\text {th }}$ and $14^{\text {th }}$. It can be observed from
Table 5 Comparison of $\Delta R S I(r)$ calculated from delta analysis and conventional method for Test case-4

\begin{tabular}{lllll}
\hline Sl. No & Bus No & $\begin{array}{l}\Delta R S I(r) \\
\text { Due to loss of DG-I }\end{array}$ & $\begin{array}{l}\Delta R S I(r) \\
\text { Due to loss of DG-II }\end{array}$ & $\begin{array}{l}\Delta R S I(r) \\
\text { Due to loss of DG-III }\end{array}$ \\
\hline 1 & 2 & 0.0040429 & 0.002425 & 0.0029544 \\
2 & 3 & 0.0089751 & 0.0036572 & 0.0044556 \\
3 & 4 & 0.0096368 & 0.0039269 & 0.0047841 \\
4 & 5 & 0.010216 & 0.0041628 & 0.0050716 \\
5 & 6 & 0.0052375 & 0.0031416 & 0.0079597 \\
6 & 7 & 0.0055832 & 0.003349 & 0.010402 \\
7 & 8 & 0.004294 & 0.0050423 & 0.003138 \\
8 & 9 & 0.0043114 & 0.0070904 & 0.0031507 \\
9 & 10 & 0.013236 & 0.0039324 & 0.0047909 \\
10 & 11 & 0.019282 & 0.0042991 & 0.0052376 \\
11 & 12 & 0.024014 & 0.0044757 & 0.0054528 \\
12 & 13 & 0.010208 & 0.0041596 & 0.0050677 \\
13 & 14 & 0.0098664 & 0.0040204 & 0.0048981 \\
14 & 15 & 0.0053706 & 0.0032214 & 0.0081619 \\
$\sum[\Delta R S I(r)]$ & & 0.1342739 & 0.0569038 & 0.0755251 \\
\hline
\end{tabular}




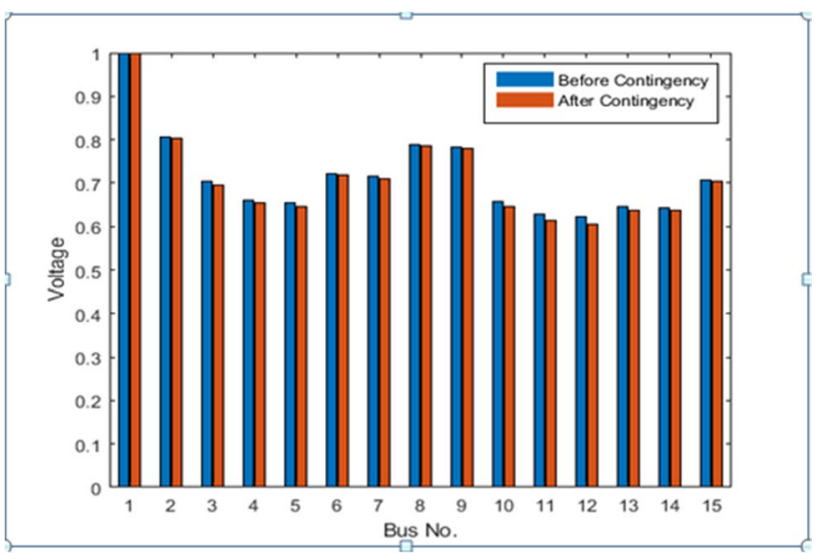

Fig. 16 With loss of DG at $12^{\text {th }}$ bus

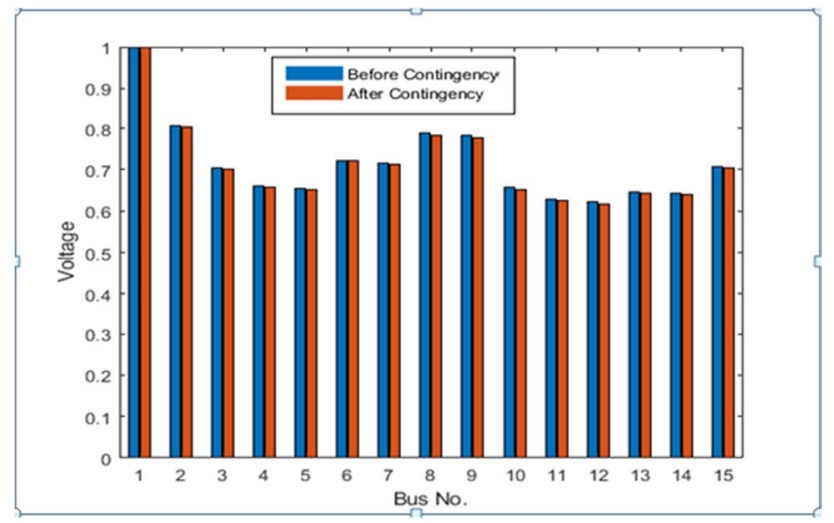

Fig. 17 With loss of DG at $9^{\text {th }}$ bus

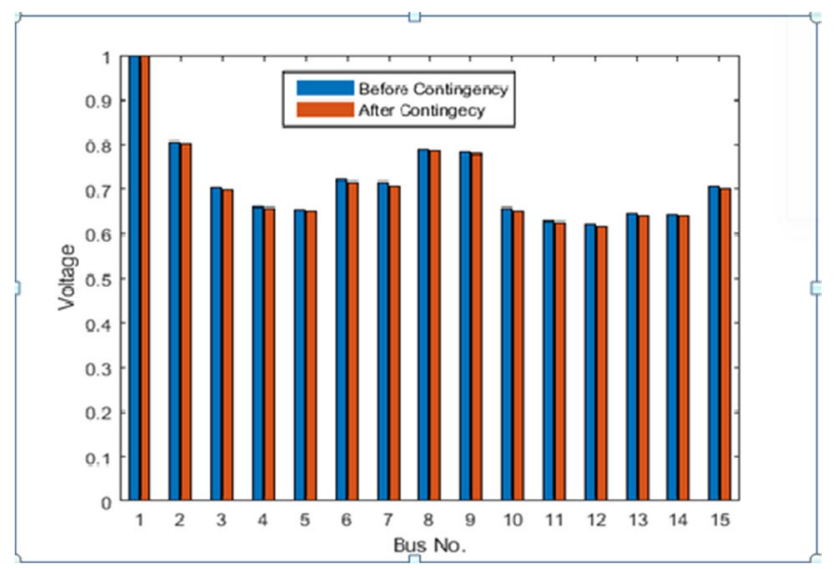

Fig. 18 With loss of DG at $7^{\text {th }}$ bus

the Fig. 19 below it is considerable development on voltage profile, then DSTATCOMs location in the 15 bus system.

Presently, DSTATCOMs are widely placed in the distribution systems for improvement of the voltages, reduction of line losses and improvement of voltage stability. 15 bus distribution system is analyzed with placement of $1500 \mathrm{kVAr}$ SVC at bus no's $12^{\text {th }}, 13^{\text {th }}$ and $14^{\text {th }}$. It can be observed from the figure below it is considerable development on voltage profile, then DSTATCOMs location in the 15 bus system.

\section{IEEE 69 Bus System}

Pattern of variation of indices for the IEEE-69 bus system is depicted in Fig. 20. The indices varied with the bus number of 0 to 69 . In the bus number of 1 to 29 , the index value like SI, RSI(r) and RSI-N(r) is varied with the value of 1 to 0.7 . In the bus number of 29 to 50 , the index value like SI, RSI(r) and RSI-N(r) gives the value of 1 . In the bus number of 50 to 70, the index value like SI, RSI(r) and RSI-N(r) is varied with the value of 1 to 0.85 .

Pattern of variation of indices for the IEEE- 69 bus system is depicted in Fig. 21. The indices varied with the bus number of 0 to 69 . In the bus number of 1 to 29 , the index value like RSI_P(r) and L-Index is varied with the value of 0 to 0.58 . In the bus number of 29 to 50 , the index value like RSI_P(r) and L-Index gives the value of 0 . In the bus number of 50 to 70, the index value like RSI_P(r) and L-Index is varied with the value of 0 to 0.11 .The bus voltage of IEEE 69 bus system is depicted in the Fig. 22. The voltage value of the IEEE 69 bus system is varied with the value of 1 to 0.958 .Application of proposed system on test system is shown in Table 6. Average Root Mean Square (ARMS) and relative errors of output calculation are depicted in Table 7.

\section{IEEE 123 System}

The indices proposed are valid for distribution systems. Indices are derived from the already existing and time tested indices proposed in the literature. Most of the distribution systems available are of short length so the negligence of shunt admittance is valid. Voltage stability indices derived in this paper are for the distribution systems with no shunt admittance. IEEE-123 bus system data shows that each line is having shunt admittance. So in order to apply the proposed method the shunt admittance is neglected which is a valid assumption. Only shunt admittance is not considered this is only assumption. Pattern of variation of indices with Bus No is given in Fig. 23.

This graph shows that the patterns of variation of 3 indices are near to comparison. L-Index is given by

$L_{j}=\left|1-\sum_{i=1}^{i=g} F_{j i} \frac{V_{i}}{V_{j}}\right|$

where $F_{L G}=\left[Y_{L L}\right]^{-1}\left[Y_{L G}\right]$. On careful observation it can be seen that as calculation of FLG matrix requires inverse of $Y$ 
Fig. 19 Voltage profile before and after placement of DSTAT$\mathrm{COMs}$

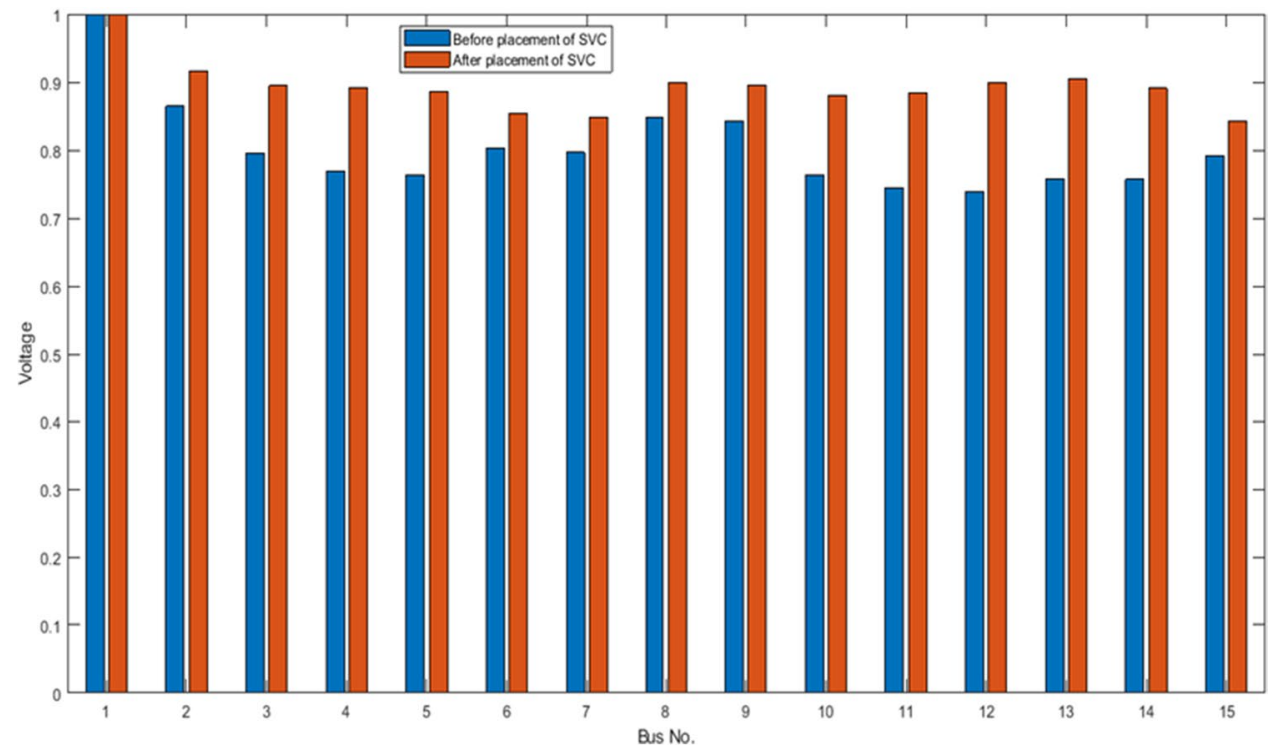

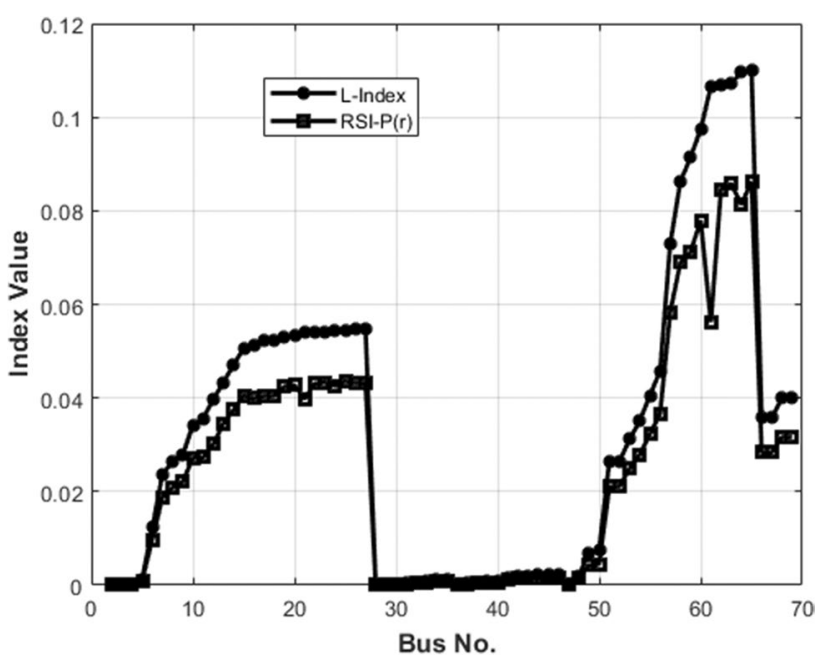

Fig. 21 Pattern of variation of RSI_P(r) and L-Index for the IEEE-69 bus system

operator is alert when any contingency occurs. The proposed method of Delta analysis is tested taking different possible contingencies experienced by the system in the real time. Contingency analysis is done taking four contingencies, with the loss of active power source, with the loss of reactive power source, with the loss of line and with the loss of multiple sources for contingency ranking. The results presented would lead to the following conclusions,

(1) To forecast the voltage system stability, the proposed system is tested under four different bus system like 15, 28 bus system, IEEE 69 and 123 bus system.

(2) To forecast the voltage stability of radial systems, two new indices are proposed. The results plotted for proposed indices and conventional indices are in close 


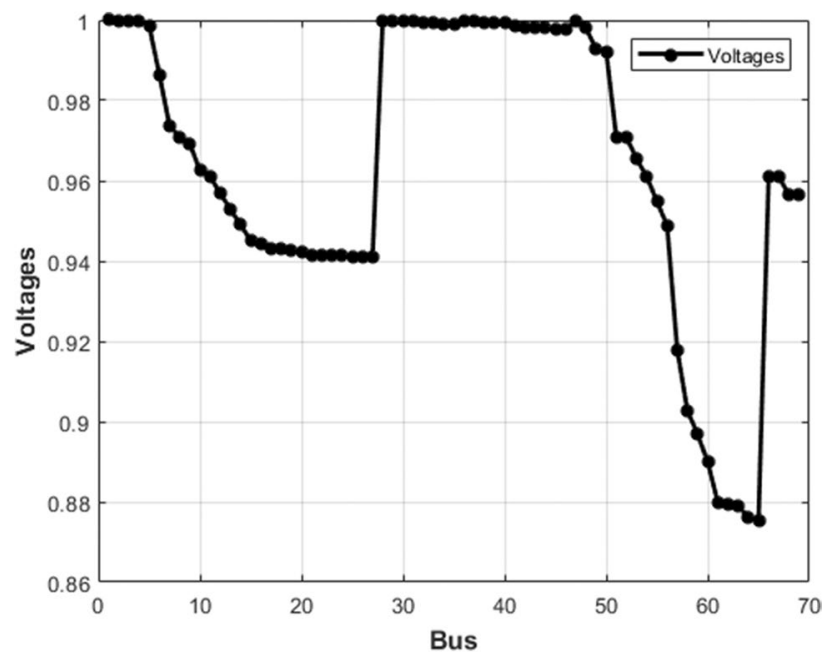

Fig. 22 Bus voltage for IEEE-69 bus system

Table 6 Application of proposed system on test system

\begin{tabular}{llc}
\hline Test System & Metrics & $\begin{array}{c}\text { IEEE 69 } \\
\text { bus system }\end{array}$ \\
\hline Mohammedi et al. (2013) & Loss reduction & - \\
& System load ability & 3.20 \\
Mohammedi et al. [17] & Loss reduction & $53.80 \%$ \\
& System load ability & 4.24 \\
Proposed system & Loss reduction & $71.90 \%$ \\
& System load ability & 2.17 \\
\hline
\end{tabular}

agreement. Hence, the proposed indices are used as new voltage stability indices.

(3) Test results obtained by implementation of Delta analysis method for different test cases are matching with the conventional method.

(4) Once $\Delta R S I(R)$ is calculated it can be used to find the ranking of any contingency quickly. It will helpful in real time and planning studies for maintaining the reliability of the supply.

It can be concluded that delta analysis method is a powerful tool for predicting the voltage system stability and improving the system reliability.Future work can be done on dynamic voltage stability analysis by considering generator dynamics and dynamic load models. Dynamic analysis can be done for contingencies and ranking can be given for buses and branches. The improvement in voltage stability by various reactive power compensation devices can be observed.

\section{Appendix 1}

Tables 9 and 10

Data Availability Data sharing does not apply to this article as no new data has been created or analyzed in this study.

Code availability Not applicable.

\section{Declarations}

The authors declare that they have no known competing financial interests or personal relationships that could have appeared to influence the work reported in this paper.

Ethical approval This article does not contain any studies with human participants performed by any of the authors.

Consent to participate Not applicable.

Conflicts of interest Authors declare that they have no conflict of interest.

\section{References}

1. Al-Shaalan AM (2020) Contingency selection and ranking for composite power system reliability evaluation. Journal of King Saud University-Engineering Sciences 32(2):141-147

2. Amjady N (2003) Dynamic voltage security assessment by a neural network based method. Electric Power Systems Research 66(3):215-226

3. Amjady N, Esmaili M (2005) Application of a new sensitivity analysis framework for voltage contingency ranking. IEEE Trans Power Syst 20(2):973-983

4. Awasthi H, Kaur M (2018) Contingency Assessment of Radial Distribution System. In2018 IEEE 8th Power India International Conference (PIICON) 1-6. IEEE

5. Bindumol EK, Babu CA (2017) Impact of D-STATCOM on voltage stability in radial distribution system. In2017 International
Table 7 Average Root Mean Square (ARMS) and relative errors of output calculation

\begin{tabular}{|c|c|c|c|c|c|}
\hline \multirow[t]{2}{*}{ Error Terms (\%) } & \multirow[t]{2}{*}{ Parameters } & \multicolumn{2}{|l|}{ Average } & \multicolumn{2}{|l|}{ Maximum } \\
\hline & & Kenari et al. [13] & Proposed & Kenari et al. [13] & Proposed \\
\hline \multirow[t]{2}{*}{ Relative error (\%) } & Mean calculation & 0.09 & 0.075 & 0.012 & 0.08 \\
\hline & SD calculation & 1.07 & 1 & 1.39 & 1.111 \\
\hline ARMS error (\%) & $\begin{array}{l}\text { Cumulative distribution } \\
\text { function (CDF) estima- } \\
\text { tion }\end{array}$ & 0.086 & 0.079 & 0.125 & 0.109 \\
\hline
\end{tabular}




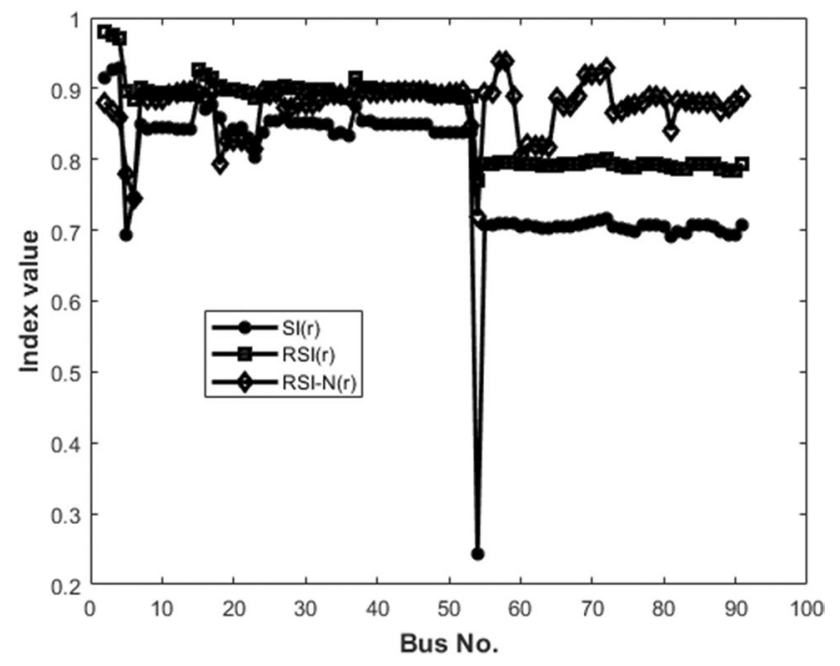

Fig. 23 Pattern of variation of indices with Bus No

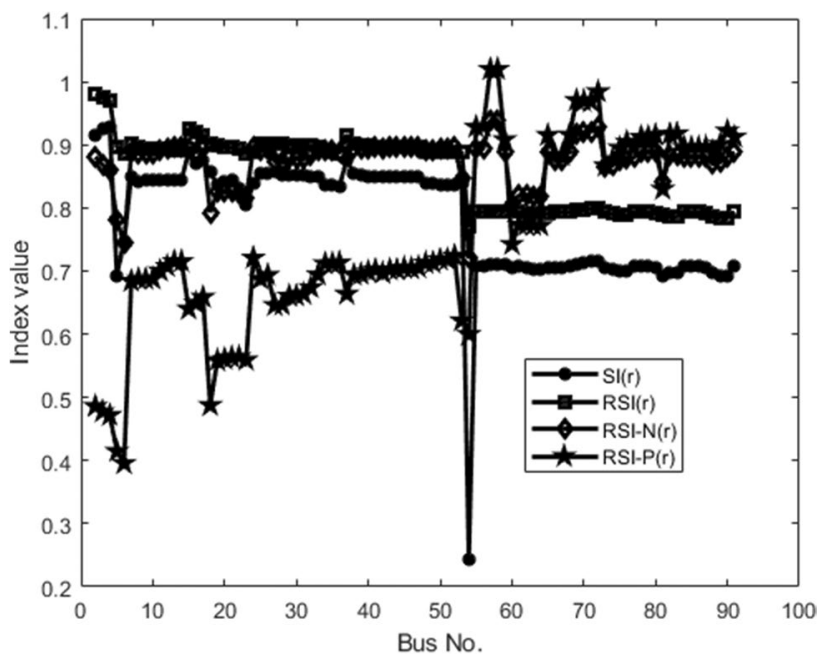

Fig. 24 Pattern of variation of indices

Conference on Energy, Communication, Data Analytics and Soft Computing (ICECDS) 841-844. IEEE

6. Cervantes CJ, Kazemtabrizi B, Troffaes MC (2018) Contingency ranking in power systems via reliability rates. In2018 IEEE International Conference on Environment and Electrical Engineering and 2018 IEEE Industrial and Commercial Power Systems Europe (EEEIC/I\&CPS Europe) 1-6. IEEE

7. Cossent R, Gómez T, Frías P (2009) Towards a future with large penetration of distributed generation: Is the current regulation of electricity distribution ready. Regulatory recommendations under a European perspective. Energy Policy 37(3):1145-55

8. Eminoglu U, Hocaoglu MH (2007) A voltage stability index for radial distribution networks. In2007 42nd International Universities Power Engineering Conference, 408-413. IEEE

9. Essallah S, Bouallegue A, Khedher A (2015) Optimal placement of PV-distributed generation units in radial distribution system based on sensitivity approaches. In2015 16th International
Conference on Sciences and Techniques of Automatic Control and Computer Engineering (STA),513-520. IEEE

10. Ettehadi M, Ghasemi H, Vaez-Zadeh S (2012) Voltage stabilitybased DG placement in distribution networks. IEEE Transactions on Power Delivery. 28(1):171-8

11. Gubina F, Strmcnik B (1997) A simple approach to voltage stability assessment in radial networks. IEEE Trans Power Syst 12(3):1121-1128

12. Jasmon GB, Lee LH (1991) Distribution network reduction for voltage stability analysis and loadflow calculations. Int J Electr Power Energy Syst 13(1):9-13

13. Kenari MT, Sepasian MS, Nazar MS (2019) Probabilistic assessment of static voltage stability in distribution systems considering wind generation using catastrophe theory. IET Gener Transm Distrib 13(13):2856-2865

14. Kommula BN, Song H, Chen L, Xu C (2021) Efficient energy management of hybrid renewable energy sources-based smartgrid system using a hybrid IDEA-CFA technique. International Transactions on Electrical Energy Systems. 31(5):e12833

15. Kotamarty S, Khushalani S, Schulz N (2008) Impact of distributed generation on distribution contingency analysis. Electric Power Systems Research 78(9):1537-1545

16. Lakshmikantha BR, Sundar KS (2018) A novel method for assessment of voltage stability improvement of radial distribution system using SVC at optimal location. In2018 International Conference on Electrical, Electronics, Communication, Computer, and Optimization Techniques (ICEECCOT), 602-606. IEEE

17. Mohammedi R. D, Hellal A, Arif S, Mosbah, M. (2013). Optimal DG placement and sizing in radial distribution systems using NSGA-II for power loss minimization and voltage stability enhancement.International Review of Electrical Engineering, $8(06)$

18. Musirin I, Rahman TA (2003) Fast automatic contingency analysis and ranking technique for power system security assessment. InProceedings.Student Conference on Research and Development, 2003.SCORED 2003,231-236. IEEE

19. Mythili S, Thiyagarajah K, Rajesh P, Shajin FH. (2020). Ideal position and size selection of unified power flow controllers (UPFCs) to upgrade the dynamic stability of systems: 27(1):25-37

20. Prada RB, Souza LJ (1998) Voltage stability and thermal limit: constraints on the maximum loading of electrical energy distribution feeders. IEE Proceedings-Generation, Transmission and Distribution 145(5):573-577

21. Rajesh P, Shajin F (2020) A Multi-Objective Hybrid Algorithm for Planning Electrical Distribution System 22(4-5):224-509

22. Ranjan R, Das D (2003) Voltage stability analysis of radial distribution networks. Electric Power Components and Systems 31(5):501-511

23. Shajin FH, Rajesh P. (2020). Trusted secure geographic routing protocol: outsider attack detection in mobile ad hoc networks by adopting trusted secure geographic routing protocol

24. Singh B, Agrawal G (2018) Enhancement of voltage profile by incorporation of SVC in power system networks by using optimal load flow method in MATLAB/Simulink environments. Energy Rep 4:418-434

25. Thota MK, Shajin FH, Rajesh P (2020) Survey on software defect prediction techniques 17(4):331-344

26. Union E (2009) Directive 2009/28/EC of the European Parliament and of the Council of 23 April 2009 on the promotion of the use of energy from renewable sources and amending and subsequently repealing Directives 2001/77/EC and 2003/30/EC. Off J Eur Union 5:2009

Publisher's Note Springer Nature remains neutral with regard to jurisdictional claims in published maps and institutional affiliations. 
Table 8 Bus Voltages on IEEE 123 Bus System (R-Phase)

\begin{tabular}{|c|c|c|c|c|c|c|c|}
\hline Bus No & Voltages & Bus No & Voltages & Bus No & Voltages & Bus No & Voltages \\
\hline 1 & 1 & 26 & 0.974029853 & 51 & 0.97075052 & 76 & 0.942141631 \\
\hline 2 & 0.996919791 & 27 & 0.974772472 & 52 & 0.97075052 & 77 & 0.943808369 \\
\hline 3 & 0.994943116 & 28 & 0.974286054 & 53 & 0.971171645 & 78 & 0.943808369 \\
\hline 4 & 0.99350905 & 29 & 0.97403958 & 54 & 0.944049085 & 79 & 0.943808369 \\
\hline 5 & 0.981351036 & 30 & 0.973793139 & 55 & 0.944036202 & 80 & 0.94334346 \\
\hline 6 & 0.974772472 & 31 & 0.973611559 & 56 & 0.94402694 & 81 & 0.9418762 \\
\hline 7 & 0.973892151 & 32 & 0.973423503 & 57 & 0.9443403 & 82 & 0.941736495 \\
\hline 8 & 0.972537989 & 33 & 0.973372924 & 58 & 0.944418655 & 83 & 0.941468733 \\
\hline 9 & 0.972427936 & 34 & 0.970826874 & 59 & 0.94437622 & 84 & 0.943867546 \\
\hline 10 & 0.972310983 & 35 & 0.970783947 & 60 & 0.943855538 & 85 & 0.943825067 \\
\hline 11 & 0.972233081 & 36 & 0.970332121 & 61 & 0.943855538 & 86 & 0.94378259 \\
\hline 12 & 0.971962444 & 37 & 0.978216285 & 62 & 0.943704902 & 87 & 0.943527029 \\
\hline 13 & 0.971962444 & 38 & 0.974184966 & 63 & 0.943539226 & 88 & 0.941643245 \\
\hline 14 & 0.971962444 & 39 & 0.973914871 & 64 & 0.94334346 & 89 & 0.94090931 \\
\hline 15 & 0.980791305 & 40 & 0.973431393 & 65 & 0.94334346 & 90 & 0.940757853 \\
\hline 16 & 0.978328329 & 41 & 0.973296261 & 66 & 0.943958512 & 91 & 0.94378259 \\
\hline 17 & 0.978282813 & 42 & 0.973361903 & 67 & 0.943919467 & 86 & 0.94378259 \\
\hline 18 & 0.974772472 & 43 & 0.973342453 & 68 & 0.943893592 & 87 & 0.943527029 \\
\hline 19 & 0.973895277 & 44 & 0.973323003 & 69 & 0.944880479 & 88 & 0.941643245 \\
\hline 20 & 0.973488322 & 45 & 0.973323003 & 70 & 0.945342377 & 89 & 0.94090931 \\
\hline 21 & 0.973253587 & 46 & 0.97323219 & 71 & 0.945585511 & 90 & 0.940757853 \\
\hline 22 & 0.972589972 & 47 & 0.97323219 & 72 & 0.945875748 & 91 & 0.94378259 \\
\hline 23 & 0.971171645 & 48 & 0.971040215 & 73 & 0.943490907 & & \\
\hline 24 & 0.971171645 & 49 & 0.970948214 & 74 & 0.942851248 & & \\
\hline 25 & 0.974322422 & 50 & 0.970858932 & 75 & 0.942397568 & & \\
\hline
\end{tabular}

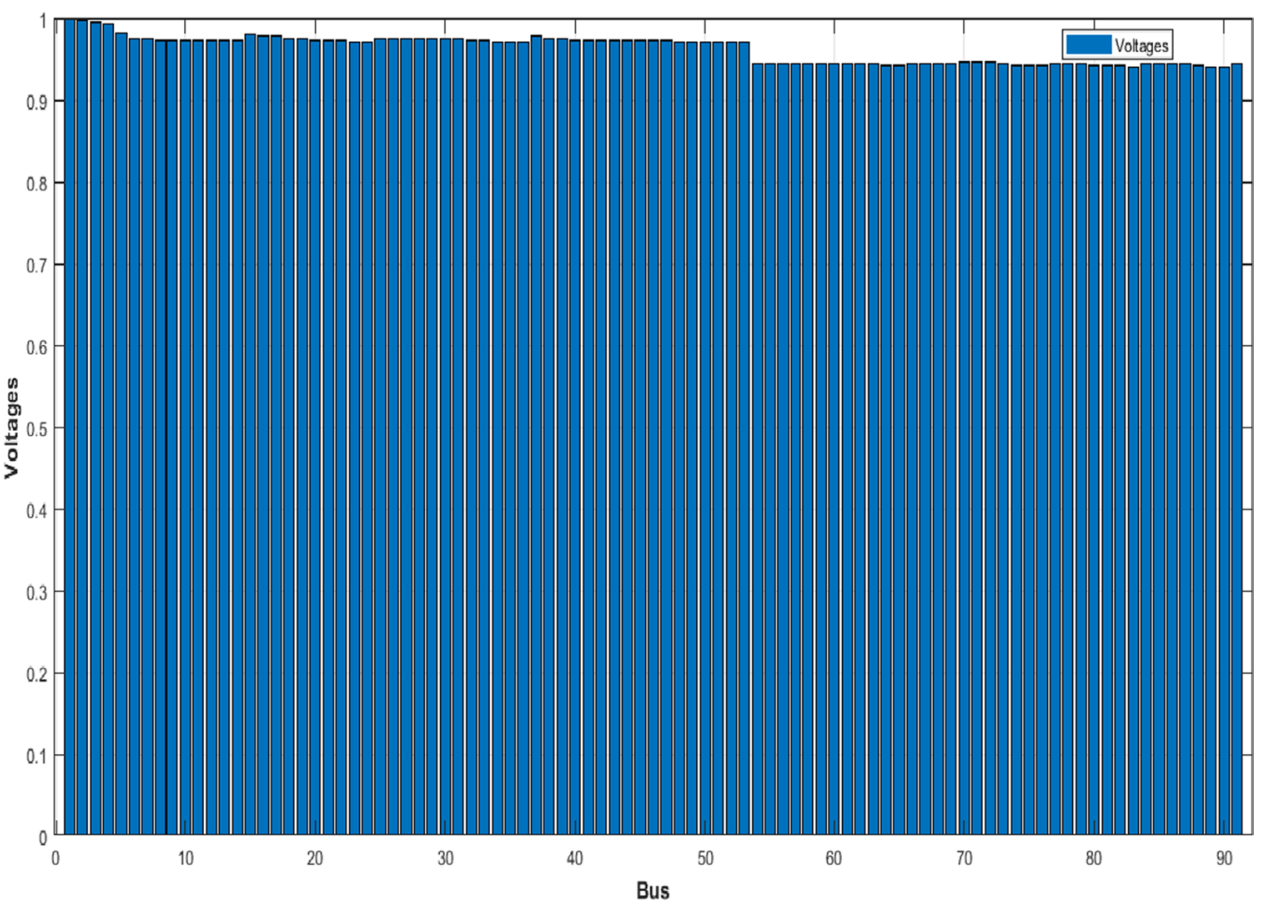

Fig. 25 Voltage profile of IEEE 123 bus system 
Table 9 Line data and nominal load data of 15 bus system

\begin{tabular}{lllllll}
\hline Branch No & $\begin{array}{l}\text { Sending } \\
\text { end node }\end{array}$ & $\begin{array}{l}\text { Receiving } \\
\text { end node }\end{array}$ & Branch resistance & Branch reactance & \multicolumn{2}{l}{$\begin{array}{l}\text { Nominal load } \\
\text { Receiving end }\end{array}$} \\
\cline { 4 - 6 } & & & & & P KW & $\begin{array}{l}\text { Q } \\
\text { kVAr }\end{array}$ \\
\hline 1 & 1 & 2 & 1.35310 & 1.32350 & 44.2 & 44.2 \\
2 & 2 & 3 & 1.17031 & 1.14471 & 70 & 70 \\
3 & 3 & 4 & 0.84122 & 0.82280 & 141 & 141 \\
4 & 4 & 5 & 1.52350 & 1.02771 & 44.2 & 44.2 \\
5 & 2 & 8 & 2.01320 & 1.35789 & 70 & 70 \\
6 & 8 & 9 & 1.68682 & 1.13781 & 44.2 & 44.2 \\
7 & 2 & 6 & 2.55731 & 1.72489 & 141 & 141 \\
8 & 6 & 15 & 1.0891 & 0.73411 & 141 & 141 \\
9 & 6 & 7 & 1.25151 & 0.84421 & 70 & 70 \\
10 & 3 & 10 & 1.79561 & 1.21121 & 141 & 141 \\
11 & 10 & 11 & 2.44851 & 1.65161 & 70 & 70 \\
12 & 11 & 12 & 2.01328 & 1.35789 & 44.2 & 44.2 \\
13 & 4 & 13 & 2.23090 & 1.50489 & 70 & 70 \\
14 & 4 & 14 & 1.19711 & 0.80751 & 141 & 141 \\
\hline
\end{tabular}


Table 10 Line data and nominal load data of 28 bus system

\begin{tabular}{|c|c|c|c|c|c|c|}
\hline \multirow[t]{2}{*}{ Branch No } & \multirow[t]{2}{*}{$\begin{array}{l}\text { Sending } \\
\text { end node }\end{array}$} & \multirow[t]{2}{*}{$\begin{array}{l}\text { Receiving } \\
\text { end node }\end{array}$} & \multirow[t]{2}{*}{ Branch resistance } & \multirow[t]{2}{*}{ Branch reactance } & \multicolumn{2}{|c|}{$\begin{array}{l}\text { Nominal load } \\
\text { Receiving end }\end{array}$} \\
\hline & & & & & P KW & $\begin{array}{l}\mathrm{Q} \\
\mathrm{kVAr}\end{array}$ \\
\hline 1 & 1 & 2 & 1.8227 & 0.761 & 141 & 90 \\
\hline 2 & 2 & 3 & 2.231 & 0.9480 & 80 & 50 \\
\hline 3 & 3 & 4 & 1.3671 & 0.5691 & 80 & 60 \\
\hline 4 & 4 & 5 & 0.920 & 0.381 & 100 & 60 \\
\hline 5 & 5 & 6 & 3.6441 & 1.521 & 80 & 50 \\
\hline 6 & 6 & 7 & 2.7332 & 1.142 & 90 & 40 \\
\hline 7 & 7 & 8 & 1.4584 & 0.6073 & 90 & 40 \\
\hline 8 & 8 & 9 & 2.7332 & 1.141 & 80 & 50 \\
\hline 9 & 9 & 10 & 3.6441 & 1.522 & 90 & 50 \\
\hline 10 & 10 & 11 & 2.761 & 0.781 & 80 & 50 \\
\hline 11 & 11 & 12 & 1.381 & 0.390 & 80 & 40 \\
\hline 12 & 12 & 13 & 4.134 & 1.175 & 90 & 50 \\
\hline 13 & 13 & 14 & 4.134 & 0.8564 & 70 & 40 \\
\hline 14 & 14 & 15 & 3.0272 & 0.778 & 70 & 40 \\
\hline 15 & 15 & 16 & 2.752 & 1.167 & 70 & 40 \\
\hline 16 & 16 & 17 & 4.128 & 0.778 & 60 & 30 \\
\hline 17 & 17 & 18 & 2.752 & 0.778 & 60 & 30 \\
\hline 18 & 2 & 19 & 3.44 & 0.9725 & 70 & 40 \\
\hline 19 & 19 & 20 & 1.376 & 0.389 & 50 & 30 \\
\hline 20 & 20 & 21 & 2.752 & 0.778 & 50 & 30 \\
\hline 21 & 21 & 22 & 4.9536 & 1.4004 & 40 & 20 \\
\hline 22 & 3 & 23 & 3.5776 & 1.0114 & 50 & 30 \\
\hline 23 & 23 & 24 & 3.0272 & 0.8558 & 50 & 20 \\
\hline 24 & 24 & 25 & 5.504 & 1.556 & 60 & 30 \\
\hline 25 & 6 & 26 & 2.752 & 0.778 & 40 & 20 \\
\hline 26 & 26 & 27 & 1.376 & 0.389 & 40 & 20 \\
\hline 27 & 27 & 28 & 1.376 & 0.389 & 40 & 20 \\
\hline 1 & 1 & 2 & 1.8216 & 0.758 & 140 & 90 \\
\hline
\end{tabular}

